\title{
Gestão de Carreiras no Setor Público Mineiro: o caso dos Especialistas em Políticas Públicas e Gestão Governamental
}

\section{Career Management in the Public Sector of Minas Gerais: the case of Specialists in Governmental Management and Public Policies}

Resumo

0 objetivo do presente artigo é enumerar e analisar as políticas e práticas de recursos humanos existentes para os especialistas em políticas públicas e gestão governamental (EPPGG) do Estado de Minas Gerais, na percepção desses profissionais. Para tal, foi promovida uma verificação das mudanças sofridas por essas políticas, indicando possível melhoria ou retrocesso. Quanto ao tipo, a pesquisa apresenta caráter exploratório e descritivo; já quanto aos meios, constitui-se em um estudo de caso. Assim, foi realizada uma pesquisa quantitativa, por meio da aplicação de questionário à amostra representativa dos EPPGG, membros da carreira e exmembros. Em virtude da pesquisa, pôde-se concluir que, da totalidade de políticas e práticas de recursos humanos listadas, apenas 28,6\% são visualizadas como políticas e práticas implementadas pelo Governo de Minas, na percepção dos membros da carreira. Por meio da pesquisa, concluiu-se, também, que $71,4 \%$ das políticas e práticas de recursos humanas analisadas sofreram melhora e $21,4 \%$ sofreram retrocesso, se analisadas as diferenças de percepções dos membros e ex-membros.

Palavras-chave: gestão de pessoas; gestão de carreiras; percepção; EPPGG; Minas Gerais.

Kamila Pagel de Oliveira - kamilapagel@yahoo.com.br

Graduada em Administração Pública pela Escola de Governo da Fundação João Pinheiro e mestre e doutoranda em Administração de Empresas pela UFMG. É especialista em Políticas Públicas e Gestão Governamental no Estado de Minas Gerais. Subcoordenadora e professora do curso de Administração Pública da Escola de Governo da Fundação João Pinheiro.

Ivan Beck Ckagnazaroff - ivanbeck@face.ufmg.br

Graduado em Economia pela PUC Minas, mestre em Administração pela UFMG e doutor em Doctoral Programme Aston Business School pela Aston University. Atua como professor adjunto da Faculdade de Ciências Econômicas, Departamento de Ciências Administrativas, da Universidade Federal de Minas Gerais e pesquisador do Conselho Nacional de Desenvolvimento Científico e Tecnológico.

Mauro César da Silveira - maurocsilveira@hotmail.com

Graduado em Direito e Administração, mestre em Engenharia de Produção e doutorando em Administração de Empresas pela UFMG. É especialista em Políticas Públicas e Gestão Governamental no Estado de Minas Gerais. Assessor na Secretaria de Planejamento e Gestão do Estado de Minas Gerais e professor da Escola de Governo da Fundação João Pinheiro.

Carlos Eduardo Simões Moraes - carlosesm@hotmail.com

Graduando em Direito pela Universidade Federal de Minas Gerais e graduando em Administração Pública pela Escola de Governo da Fundação João Pinheiro. Escola de Governo da Fundação João Pinheiro.

Artigo submetido no dia 16 de maio-de 2012 e aprovado em 19 de abril de 2013 


\section{ABSTRACT}

The aim of this paper is to list and analyze existing human resource policies and practices for specialists in public policy and government management (EPPGG) of the State of Minas Gerais in the perception of these professionals. The changes that occurred due to these policies were verified, indicating a possible improvement or retrogression. Regarding the type of research, an exploratory and a descriptive study are used, consisting of a case report. Thus, a quantitative survey was conducted using a questionnaire for a representative sample of EPPGG, career members and former members. This research indicated that from the totality of policies and practices of human resources listed, only $28.6 \%$ are viewed as policies and practices implemented by the Government of Minas Gerais, in the perception of career members. Through the research, it was also found that $71.4 \%$ of the policies and practices of human resources analyzed experienced improvement, and $21.4 \%$ suffered setbacks, when examining the differences in perceptions of members and former members.

Keywords: Human resource management, career management, perception, EPPGG, Minas Gerais.

\section{Introdução}

A década de 1990 consolidou-se como um período crucial para a gestão de pessoas. A realidade econômica globalizada pressionou por mudanças no foco da área, no sentido de reduzir as funções administrativas e de ampliar as funções estratégicas, ligadas aos objetivos mais amplos da organização (ULRICH et al., 2001).

Albuquerque (1987) explica que a gestão estratégica de recursos humanos envolve um processo decisório amplo, com visão de futuro e direcionado às variações do ambiente externo. Tendo em vista a integração dos objetivos organizacionais e das políticas que embasam os diversos processos da organização, a área de recursos humanos tem como prerrogativa assessorar as demais áreas para a consecução dos objetivos organizacionais, melhoria ou retrocesso. Quanto ao tipo, a pesquisa apresenta caráter exploratório e descritivo.

As transformações percebidas no mundo do trabalho impactam, de maneira significativa, o emprego público, em maior ou menor grau. Nas palavras de Longo: "os novos enfoques de gestão de recursos humanos nas empresas alimentam os planos de modernização da gestão pública" (LONGO, 2007, p. 53).

A necessidade de inovação da gestão de pessoas no setor público destaca-se na análise dos esforços quando abordadas a Reforma do Estado e a introdução de práticas gerenciais, no âmbito das organizações públicas. Os esforços para reduzir os efeitos perversos da burocracia e atingir uma modernização administrativa e, em última instância, a eficiência e eficácia dos serviços públicos significaram, em um primeiro momento, a adoção de políticas de redução de custos e de pessoal, mas, posteriormente, passaram a refletir a demanda por profissionais competentes e qualificados (PEREIRA, 1998; MARCONI, 2005; RAMIÓ; SALVADOR, 2008).

Inserida nesse novo cenário, a área de recursos humanos das instituições públicas também possui o desafio de atrair, desenvolver, motivar e reter seus profissionais para alcançar bons resultados e permitir a efetivação da modernização do setor público.

Para o alcance desses objetivos, as questões relacionadas à gestão de pessoas devem girar em torno do desenvolvimento e da aplicação de políticas inovadoras de recrutamento e seleção, do desenvolvimento de pessoal, do desenvolvimento de carreira, do plano de cargos e dos salários, qualidade de 
vida, remuneração e benefícios, e da integração desses subsistemas em um sistema de gestão de pessoas integrado e coeso.

A problemática deste estudo consistiu em enumerar e analisar as políticas e as práticas de recursos humanos existentes para os EPPGG do Estado de Minas Gerais, com base na percepção desses profissionais. Buscou-se verificar, também, a percepção dos EPPGG quanto a possíveis mudanças na implementação dessas políticas, tais como melhoria ou retrocesso, contemplando o período de 1992 a 2009. O ano de 1992 configura-se como o período de nomeação dos primeiros EPPGG de Minas Gerais, então chamados de administradores públicos. $O$ ano de 2009 caracteriza o momento no qual foram coletados os dados desta pesquisa.

O cargo de EPPGG de Minas Gerais foi criado pela Lei 13.085 (MINAS GERAIS, 1998), em substituição ao cargo de administrador público, e é atualmente regulamentado pela Lei 18.974 (MINAS GERAIS, 2010), com o objetivo de formar profissionais qualificados para 0 exercício de atividades relacionadas à gestão governamental e à formulação, implementação e avaliação de políticas públicas. De acordo com a Lei 18.974/2010, são atribuições do EPPGG: a formulação, supervisão e avaliação de políticas públicas e o exercício de atividades relacionadas às áreas de planejamento e avaliação, administração financeira e orçamentária, contabilidade, modernização da gestão, racionalização de processos, gestão e tecnologia da informação, recursos logísticos, recursos materiais, recursos humanos e administração patrimonial (MINAS GERAIS, 2010).

O EPPGG é formado pela Escola de Governo da Fundação João Pinheiro e possui benefícios que se caracterizam pela oferta de uma bolsa de estudos mensal e pela garantia de emprego, pelo ingresso automático em algum órgão público mineiro, quando da conclusão do curso de graduação em administração pública. Em contrapartida a esses benefícios, ao ser nomeado, o aluno graduado compromete-se a trabalhar no Estado durante o período mínimo de dois anos. Caso não cumpra esse critério, terá que restituir aos cofres públicos o investimento no valor correspondente aos quatro anos de estudo.

Os EPPGG constituem-se em uma carreira estratégica para o Governo de Minas Gerais, visto que são responsáveis pela coordenação de projetos e iniciativas de inovação e modernização do setor público mineiro, consolidados no Programa Choque de Gestão. Tal relevância é reconhecida por gestores da carreira e por dirigentes da administração pública estadual. De maneira prática, a importância dos EPPGG pode ser percebida pelo fato de que esses profissionais ocupam cargos diretivos e estratégicos na administração pública mineira, inclusive cargos de alto nível do governo, como de secretário e subsecretário, além de possuírem à sua disposição grande parte dos cargos em comissão de livre nomeação (BERNARDO, 2010; CAMPOS; BERNARDI, 2008).

Os EPPGG, comumente chamados de "administradores públicos", em referência à primeira denominação do cargo, são intensamente demandados pelas secretarias de Estado, por possuírem formação na área pública e, portanto, apresentarem, de modo geral, bons desempenhos em suas atuações e funções, reforçando sua importância para a gestão pública mineira.

Por essa relevância, considerouse importante analisar a percepção dos EPPGG, sejam ativos ou exonerados, acerca da existência de políticas e práticas de recursos humanos direcionadas para esses 
profissionais. De acordo com Oliveira et al. (2009), analisando a carreira de EPPGG, porém de nível federal, a sua compreensão como um processo em movimento é fator primordial para se alcançarem os resultados institucionais e profissionais desejados pela instituição, devendo-se, para tal, levar em consideração elementos fornecidos por diagnósticos e avaliações baseados na realidade vivenciada para melhorar a gestão dessa carreira.

Em concordância com essa afirmação, acredita-se na relevância da pesquisa em questão, pois as opiniões dos EPPGG representam uma avaliação válida da realidade vivenciada na gestão desses profissionais.

\section{Gestão de Recursos Humanos na Atualidade}

A maneira como as organizações gerenciam as pessoas está passando por transformações em todo o mundo, desde meados da década de 1980. Essas mudanças estão, em grande medida, relacionadas ao aumento da competitividade e à intensificação da globalização, que vêm provocando inadequações nos modelos tradicionais de gestão de pessoas no que diz respeito às demandas e expectativas das empresas e das pessoas (DUTRA, 2004; BARBOSA et al., 2005).

Nesse contexto, surge a necessidade de desenvolver uma gestão de pessoas na qual os objetivos e as orientações estejam alinhados com as prioridades estratégicas da organização e que conduzam suas ações e os comportamentos dos indivíduos de maneira coerente com as mesmas prioridades. Ademais, a aproximação da gestão de pessoas com a estratégia organizacional perpassa o reconhecimento de que as macroestratégias organizacionais não podem ser definidas sem uma análise dinâmica da capacidade interna na dimensão humana (LONGO, 2007).

De acordo com Lacombe e Tonelli (2005), o papel estratégico a ser desempenhado pela área de gestão de pessoas envolve repensar as atividades características da área, de modo a integrar os objetivos de longo prazo da organização, as variáveis relevantes do ambiente e as necessidades decorrentes em termos de pessoas. Assim, para esses autores, em uma perspectiva estratégica, o modelo de gestão de pessoas não se restringe apenas ao caráter instrumental da gestão, mas considera também um componente real e dinâmico, cuja atuação é, ao mesmo tempo, política, social, ideológica e comportamental.

Toda essa transformação percebida na gestão de pessoas está associada à valorização dos indivíduos como ativos intangíveis da organização. De acordo com Dutra (2004, p. 14), "quanto mais as organizações buscam flexibilidade e velocidade decisória, mais dependem das pessoas." Nesse contexto, temse a necessidade de valorizar as pessoas e a percepção de que estas são fundamentais para o alcance dos resultados e para a vantagem competitiva, o que impacta a maneira de gerenciá-las e conduzi-las aos objetivos organizacionais.

Entre as transformações sofridas pela gestão de pessoas nos últimos anos, talvez uma das mais importantes seja a adoção da atual concepção de políticas integradas de gestão de recursos humanos. Nessa concepção, não é suficiente a mera definição de regras isoladas para recrutar, contratar, remunerar e capacitar, mas, além disso, é necessário que as políticas de recursos humanos sejam formuladas tendo como base as mesmas premissas e princípios, caracterizando a integração entre as políticas (ALBUQUERQUE, 1987; MARCONI, 2005; LONGO, 2007). 
Os enfoques e critérios usados para a categorização dos subsistemas que compõem a gestão integrada de recursos humanos não são uniformes. Embora grande parte dos autores reconheça a existência das mesmas funções para a administração de recursos humanos, a terminologia e o agrupamento dessas funções são realizados de maneiras diversas.

Nesta pesquisa, foi adotada a categorização definida por Longo (2007), que compreende a gestão de pessoas como sendo composta por sete subsistemas interligados entre si e alinhados à estratégia organizacional. O autor identifica os seguintes subsistemas: planejamento de recursos; organização do trabalho; gestão do emprego; gestão do desempenho; gestão da compensação; gestão do desenvolvimento; e gestão das relações humanas e sociais (LONGO, 2007).

A presente pesquisa analisou as políticas dos cinco últimos subsistemas, que se relacionam à retenção e manutenção de profissionais nas organizações, brevemente delineados da seguinte maneira:

- Subsistema de gestão do emprego: está diretamente relacionado à gestão dos fluxos, por meio do qual as pessoas entram na organização, se movimentam por ela e saem dela. Pode ser divido em três áreas principais: gestão da incorporação, gestão da mobilidade e gestão da desvinculação (LONGO, 2007).

- Subsistema de gestão do desempenho: tem o propósito de influenciar e impactar o desempenho dos funcionários, provocando o alinhamento de suas ações às prioridades da organização e ampliando a contribuição de cada um à estratégia organizacional. Pensando em um sistema integrado de gestão de pessoas, a gestão do desempenho deve estar conectada à gestão da compensação e do desenvolvimento
(LEVINSON, 1997; DUTRA, 2007; LONGO, 2007).

- Subsistema de gestão da compensação: inclui o conjunto de compensações retributivas, salariais e extrassalariais, e não retributivas que a organização oferece aos seus funcionários (LONGO, 2007). Busca recompensar o funcionário, conforme a contribuição, sem comprometer a competitividade da empresa ou o orçamento público e os limites da Lei de Responsabilidade Fiscal (LRF). Para a gestão da compensação, é preciso considerar não apenas as necessidades estratégicas da organização mas também as expectativas dos funcionários (RABELOSANTOS, 2010).

- Subsistema de gestão do desenvolvimento: tem como objetivo incentivar o crescimento profissional das pessoas, conforme o potencial de cada uma, estimulando o aprendizado individual e organizacional, e definindo os itinerários de carreira que associem as demandas da organização às necessidades e expectativas individuais (LONGO, 2007).

- Subsistema de gestão das relações humanas e sociais: dedica-se ao gerenciamento das relações firmadas entre a organização e seus funcionários, que possuem caráter coletivo. Contempla a importância das relações sociais na organização e parte do pressuposto de que "uma pessoa nunca pode dissociar aquilo que é da sua relação com os outros" (AMBLARD, 1989, p. 45). Abrange, ainda, o fato de que o indivíduo possui necessidades sociais, de estima e realização pessoal (MASLOW, 1954).

\section{Gestão de Recursos Humanos no}




\section{Setor Público Mineiro}

Com as transformações iniciadas a partir da década de 1980, orientadas para a reforma do Estado, a área de recursos humanos passou a ser focalizada. Nesse momento, em conformidade com as premissas neoliberais, intensificaram-se as pressões pela redução do aparato do Estado que apontavam para a redução dos gastos públicos com pessoal, caracterizando-se como medida essencial à reestruturação das finanças públicas e à liberação de recursos para investimentos produtivos no âmbito social (GAETANI, 1998).

Cabe destacar, porém, que estas premissas são alvo de críticas, por parte de autores que argumentam que as ações implementadas no contexto de reforma do Estado não levaram a uma diminuição significativa dos gastos públicos e do tamanho do Estado, e, ainda, que a área social não foi efetivamente priorizada, como propunham os neoliberais (PAULA, 2005; COSTA, 2006). De acordo com Costa (2006, p. 7), o novo estilo de governo, caracterizado no contexto de crise do Estado, é marcado pela "prioridade absoluta ao ajuste fiscal, com cortes expressivos nos gastos sociais," configurando uma agenda negativa de reforma.

No que tange à área de gestão de pessoas, tem-se que, nas primeiras iniciativas de reforma, a preocupação central estava relacionada à necessidade de reduzir a folha de pagamentos e de downsizing em detrimento da reformulação de políticas de gestão de pessoas que, efetivamente, conferissem relevância no que tange à profissionalização e ao desenvolvimento dos recursos humanos. Essas ações configuramse, inclusive, como um reforço do foco no ajuste fiscal, empreendido por grande parte dos governos.
Após a percepção de que as políticas de downsizing não alcançaram os objetivos de eficiência e modernização pretendidos pelas reformas, alguns autores argumentam que maior preocupação vem sendo dada à reformulação das políticas de gestão de pessoas, com o entendimento de que as reais mudanças na qualidade dos serviços públicos somente ocorrerão por meio de investimentos em profissionalização e desenvolvimento dos recursos humanos (GAETANI, 1998; NOGUEIRA; SANTANA, 2002; RAMIÓ, 2008).

Seguindo essa tendência e buscando implementar um modelo de gestão que promova a transformação das condutas e comportamentos dos indivíduos e o alinhamento diante das demandas da sociedade, o Governo de Minas Gerais implantou, de maneira formal, a partir de 2003, o programa denominado "Choque de Gestão", como uma tentativa de realização de uma reforma gerencial na administração pública mineira. Nesse sentido, de acordo com os idealizadores do programa, procurou-se estabelecer um modelo de "gestão capaz de respostas mais rápidas, mais focado no cliente/beneficiário, orientado para o resultado, flexível e transparente" (VILHENA et al., 2006, p. 30).

Assim, na percepção dos gestores e idealizadores do Choque de Gestão, três medidas foram adotadas, no intuito de melhorar a gestão de pessoas no Estado de Minas Gerais, a saber: a implementação da avaliação de desempenho individual; a reestruturação das carreiras; e o realinhamento de competências (VILHENA et al., 2006).

Regulamentada pelo Decreto 43.672 (MINAS GERAIS, 2003b), a Avaliação de Desempenho Individual (ADI) foi instituída no sentido de conformar-se como um instrumento de aplicação do modelo meritocrático na administração pública, cujos objetivos estavam voltados para: aplicação de um sistema de 
avaliação consistente, baseado nos resultados dos servidores; aprimoramento do desempenho dos servidores; valorização, reconhecimento e compensação do desempenho eficiente dos servidores; identificação das necessidades de capacitação dos servidores; e alinhamento das metas individuais com as institucionais e macrogovernamentais (VILHENA et al., 2006).

No que tange à reestruturação das carreiras, por meio do Decreto 43.576 (MINAS GERAIS, 2003a), foi instituída a reformulação de todos os planos de carreira do Estado de Minas Gerais, abrangendo 128 carreiras e aproximadamente 300 mil cargos. Entre algumas medidas adotadas, sob a ótica dos idealizadores do programa, podemse destacar: definição e padronização de conceitos relacionados à carreira, promoção e progressão; padronização da denominação das carreiras conforme o nível de escolaridade do cargo; vedação do ingresso por concurso público em cargos de carreiras com exigência de nível fundamental de escolaridade; e aumentos dos vencimentos (VILHENA et al., 2006).

Por fim, tem-se o realinhamento de competências, que, segundo os implementadores do Choque de Gestão, tem como pressuposto a inserção da gestão por competências no Estado de Minas Gerais. Associados à implementação da gestão por competência, buscou-se adotar vários outros instrumentos relacionados à gestão de recursos humanos, com o objetivo de conformarem-se como ações inovadoras na área de gestão de pessoas. Entre estes, podem ser destacados: inserção da avaliação $360^{\circ}$; certificação ocupacional; investimento em política de desenvolvimento dos servidores; e universidade corporativa, além dos instrumentos já mencionados de avaliação de desempenho individual e reestruturação das carreiras baseada no mérito (VILHENA et al.,
2006).

Fazendo referência às políticas
e práticas de gestão de pessoas implementadas em Minas Gerais, Marconi (2010, p. 272) afirma que:

A atual gestão do governo deste estado implementou uma série de medidas que mudou substancialmente a gestão de recursos humanos, realizando o chamado alinhamento estratégico entre as metas das organizações, a política de recursos humanos e os incentivos, vinculado-os fortemente ao alcance de resultados.

Não obstante o reconhecimento dos resultados alcançados por Minas Gerais a partir do Choque de Gestão, é importante salientar alguns limites relacionados não apenas a essa experiência mineira mas também a outras que buscaram a implementação de uma reforma de cunho gerencial. Assim, de acordo com Paula (2005), as reformas gerencialistas, de uma maneira geral, reforçam a dicotomia entre política e administração, ignoram a dimensão sociopolítica da gestão, incentivam a centralização do poder, além de pressupor uma superioridade das técnicas e práticas do setor privado que é passível de questionamento, podendo ser vista como um mito dos "modismos gerenciais." Outro mito destacado por Paula (2005, p. 94) refere-se ao fato de que essas ações, muitas vezes disseminadas como características de organizações "pósmoderna" ou "pós-burocrática", são mais bem entendidas se tratadas como uma adaptação da burocracia, tendo em vista que as bases da burocracia permanecem ainda no modelo gerencial. Questiona-se, portanto, o caráter inovador de muitas das políticas e ações propostas para as reformas gerenciais.

Inserido nesse contexto, sabe-se 
que muitos são os desafios relacionados à inovação da gestão de pessoas na administração pública mineira, principalmente, relacionados à disseminação e consolidação de uma visão sistêmica e integrada de gestão de pessoas. Além disso, conforme destaca Vasconcelos (2004), observa-se, em muitas organizações, que a implementação de políticas de gestão de pessoas de cunho mais inovador encontrase presente no discurso dos gestores, mas, na prática, essas mudanças não ocorrem de modo tão rápido.

Nesse sentido, considera-se relevante analisar a opinião dos EPPGG quanto às políticas de gestão de pessoas ditas como implementadas, pelos idealizadores do Choque de Gestão, no sentido de enumerar e analisar quais políticas e práticas de gestão de pessoas esses profissionais percebem como existentes.

\section{Metodologia de Pesquisa}

Quanto ao tipo, esta pesquisa caracteriza-se por seu caráter exploratório e descritivo. O caráter exploratório está associado à busca de maior familiaridade com o tema em questão. $O$ caráter descritivo está relacionado à preocupação com a análise e descrição das políticas e práticas de recursos humanos direcionadas aos EPPGG, percebidas por esses profissionais como implementadas em Minas Gerais.

Quanto aos meios, trata-se de um estudo de caso, cuja unidade de análise caracteriza-se pelas políticas e práticas de gestão de pessoas existentes, na percepção dos EPPGG.

Quanto aos procedimentos técnicos utilizados, esta pesquisa envolveu três principais: pesquisa bibliográfica, pesquisa documental e levantamento de campo.

A pesquisa bibliográfica englobou ideias e discussões de diferentes autores sobre: gestão de pessoas no contexto contemporâneo, subsistemas de gestão de recursos humanos e gestão de pessoas no setor público mineiro, considerando o contexto do Choque de Gestão.

A pesquisa documental envolveu a análise e apresentação de documentos institucionais elaborados pela Secretaria de Estado de Planejamento e Gestão (Seplag), responsável pela gestão da carreira selecionada. Esses documentos caracterizaram por tabelas contendo informações sobre os EPPGG e análise da legislação relacionada às políticas e práticas de recursos humanos já implementadas no Estado de Minas Gerais.

O terceiro procedimento diz respeito à realização de uma pesquisa de campo de caráter quantitativo, por meio do qual foi feito um survey, com amostra representativa da população de EPPGG. Assim, o universo pesquisado compreendeu a população de EPPGG, formados pela Escola de Governo da Fundação João Pinheiro (EG), cuja população é formada por 465 EPPGG, sendo 298 ainda membros da carreira e 167 ex-membros da carreira, portanto denominados, nesta pesquisa, "exonerados".

Para a definição das amostras de EPPGG membros e exonerados, considerouse a incidência do fenômeno em 64,09\% da população, que representa o percentual de membros da carreira, e percentagem complementar de $35,91 \%$, que representa o percentual de exonerados, com erro máximo permitido de $5 \%$, ou seja, considerando $95 \%$ de confiança. Com base nessas premissas, tem-se que a amostra é de 129 membros e 72 exonerados, totalizando $201 \mathrm{EPPGG}$.

O questionário foi composto por perguntas relacionadas à existência de políticas de recursos humanos implementadas no Estado de Minas Gerais direcionadas aos EPPGG. As 
políticas e práticas listadas basearam-se em políticas e práticas consideradas adequadas pela literatura e por pesquisas já realizadas. Para todas essas, foram feitas perguntas que remetessem, ao mesmo tempo, ao período atual, para os EPPGG membros, e ao período no qual o respondente atuava como EPPGG, para o caso dos exonerados. Ou seja, perguntas formuladas utilizando-se os tempos presente e o passado.

Desse modo, foi aplicado questionário estruturado a 223 EPPGG, obtendo-se 202 questionários válidos, sendo 129 de membros e 73 de exonerados. O questionário autoadministrado foi disponibilizado aos EPPGG, sorteados aleatoriamente, por meio eletrônico, em site especializado. Após a aplicação dos questionários aos EPPGG, os dados obtidos foram transferidos para o SPSS, onde foram tabulados e tratados. A análise dos dados da pesquisa de campo ocorreu por meio de análise interpretativa dos dados dos questionários.

\section{Apresentação e Análise dos Resultados da Pesquisa}

Neste tópico, procede-se à apresentação e análise dos resultados da pesquisa, com o objetivo de enumerar e analisar as políticas e práticas de recursos humanos existentes para os EPPGG, na percepção desses profissionais, e verificar se houve mudança na implementação dessas políticas, tais como melhoria ou retrocesso, no período de 1992 a 2009, conforme opinião dos EPPGG.

A análise foi subdivida conforme os subsistemas definidos neste artigo, como: gestão do emprego, gestão do desempenho, gestão da compensação, gestão do desenvolvimento e gestão das relações humanas e sociais.

\subsection{Gestão do emprego}

As análises das políticas e práticas de recursos humanos do subsistema de gestão do emprego baseiam-se nos dados constantes da Tabela 1.

Tabela 1 - Existência de políticas e práticas de gestão do emprego para os EPPGG

\begin{tabular}{|c|c|c|c|c|c|c|c|c|c|c|c|}
\hline \multirow[b]{2}{*}{ Condicão } & \multirow[b]{2}{*}{ Opção } & \multicolumn{2}{|c|}{$\begin{array}{c}\text { Foram utilizados } \\
\text { critérios baseados } \\
\text { no mérito para a } \\
\text { alocação? }\end{array}$} & \multicolumn{2}{|c|}{$\begin{array}{l}\text { Foram aplicados } \\
\text { procedimentos } \\
\text { adequados para } \\
\text { sua inserção no } \\
\text { órgão? }\end{array}$} & \multicolumn{2}{|c|}{$\begin{array}{c}\text { Foram utilizados } \\
\text { mecanismos de } \\
\text { mobilidade que } \\
\text { atenderam suas } \\
\text { demandas com } \\
\text { flexibilidade? }\end{array}$} & \multicolumn{2}{|c|}{$\begin{array}{l}\text { A mudança de } \\
\text { governo } \\
\text { interfere(iu) na } \\
\text { alocação ou } \\
\text { gestão enquanto } \\
\text { EPPGG? }\end{array}$} & \multicolumn{2}{|c|}{$\begin{array}{c}\text { Há melhores } \\
\text { condições de } \\
\text { trabalho para os } \\
\text { não- } \\
\text { concursados? }\end{array}$} \\
\hline & & Freq. & Perc. & Freq. & Perc. & Freq. & Perc. & Freq. & Perc. & Freq. & Perc. \\
\hline \multirow{5}{*}{ Membro } & Sim & 57 & $44,2 \%$ & 37 & $28,7 \%$ & 26 & $20,2 \%$ & 22 & $17,1 \%$ & 60 & $46,5 \%$ \\
\hline & Não & 49 & $38,0 \%$ & 86 & $66,7 \%$ & 51 & $39,5 \%$ & 37 & $28,7 \%$ & 53 & $41,1 \%$ \\
\hline & Não sei/não & & & & & & & & & & \\
\hline & se aplica & 23 & $17,8 \%$ & 6 & $4,7 \%$ & 52 & $40,3 \%$ & 70 & $54,3 \%$ & 16 & $12,4 \%$ \\
\hline & Total & 129 & $100 \%$ & 129 & $100 \%$ & 129 & $100 \%$ & 129 & $100 \%$ & 129 & $100 \%$ \\
\hline \multirow{5}{*}{ Exonerado } & Sim & 26 & $35,6 \%$ & 19 & $26,0 \%$ & 20 & $27,4 \%$ & 15 & $20,5 \%$ & 25 & $34,2 \%$ \\
\hline & Não & 35 & $47,9 \%$ & 51 & $69,9 \%$ & 24 & $32,9 \%$ & 24 & $32,9 \%$ & 23 & $31,5 \%$ \\
\hline & Não sei/não & & & & & & & & & & \\
\hline & se aplica & 12 & $16,4 \%$ & 3 & $4,1 \%$ & 29 & $39,7 \%$ & 34 & $46,6 \%$ & 25 & $34,2 \%$ \\
\hline & Total & 73 & $100 \%$ & 73 & $100 \%$ & 73 & $100 \%$ & 73 & $100 \%$ & 73 & $100 \%$ \\
\hline \multirow{5}{*}{$\begin{array}{l}\text { Membros + } \\
\text { Exonerados }\end{array}$} & Sim & 83 & $41,1 \%$ & 56 & $27,7 \%$ & 46 & $22,8 \%$ & 37 & $18,3 \%$ & 85 & $42,1 \%$ \\
\hline & Não & 84 & $41,6 \%$ & 137 & $67,8 \%$ & 75 & $37,1 \%$ & 61 & $30,2 \%$ & 76 & $37,6 \%$ \\
\hline & Não sei/ não & & & & & & & & & & \\
\hline & se aplica & 35 & $17,3 \%$ & 9 & $4,5 \%$ & 81 & $40,1 \%$ & 104 & $51,5 \%$ & 41 & $20,3 \%$ \\
\hline & Total & 202 & $100 \%$ & 202 & $100 \%$ & 202 & $100 \%$ & 202 & $100 \%$ & 202 & $100 \%$ \\
\hline
\end{tabular}

Fonte: elaborado pelos autores 
Com base nos dados da Tabela 1, observase que $39,5 \%$ dos membros e $32,9 \%$ dos exonerados afirmaram que não foram utilizados mecanismos de mobilidade que respondessem com flexibilidade às demandas e interesses pessoais, o que representa percentuais maiores do que a afirmação da existência de flexibilidade. É importante destacar que $40,3 \%$ dos membros e $39,7 \%$ dos exonerados responderam "Não se aplica", o que indica que não manifestaram o interesse de se mover entre setores do órgão em que estavam alocados ou, mesmo, entre órgãos diferentes. Dessa forma, pode-se dizer que não há flexibilidade no atendimento dos pedidos de transferência de setores e de órgãos dos EPPGG e que tal política sofreu significativa piora.

Sabe-se, por meio de pesquisa documental, que a mudança dos EPPGG entre órgãos do estado deve ser aprovada pela Seplag, órgão responsável pela gestão da carreira. Essa decisão não dependente apenas do interesse do EPPGG, do órgão de origem e possível destino do EPPGG, mas considera também o perfil do EPPGG, seu currículo e sua experiência e conhecimento em relação ao trabalho a ser desempenhado no local de interesse. Esse impedimento cria certa insatisfação naqueles que tiveram seus pedidos negados.

Cabe destacar que, de acordo com Longo (2007), é importante que a organização busque reduzir as barreiras para a transferência de seus funcionários, tornando essencial criar mecanismos que associem a mobilidade voluntária com as necessidades organizacionais, pois essas mobilidades também não podem ir de encontro a essas necessidades. Assim, a proibição da mobilidade voluntária pode ser prejudicial ao desempenho do profissional e, consequentemente, para o funcionamento da organização. Nessa mesma direção, Oliveira e outros (2009) apontam a necessidade de propiciar maior eficiência e efetividade quanto à mobilidade dos profissionais, de modo a extrair o maior valor agregado possível para o órgão no qual estão inseridos, para o governo, para a sociedade e para os próprios profissionais.

Ainda no que tange à gestão do emprego, 30,2\% dos EPPGG responderam que a mudança de governo não interferiu na sua alocação e gestão (Tabela 1). A categoria "Não se aplica" deve ser destacada, visto que foi direcionada para aqueles que, a princípio, não passaram por uma mudança de governo. Caso se considere apenas o percentual daqueles que passaram por mudanças, $62,2 \%$ afirmam que a descontinuidade administrativa provocada por mudanças de governo não impactou a alocação e a gestão dos EPPGG.

Com base nos dados da Tabela 1, podese inferir que administração pública mineira tem tratado de maneira mais impessoal a gestão dos EPPGG, visto que $20,5 \%$ dos exonerados informaram que a mudança de governo interferiu em sua alocação, em comparação com $17,1 \%$ de membros; percebe-se, portanto, uma pequena evolução no que tange a esse aspecto.

Cotejando as condições de trabalho, sejam físicas ou salariais, oferecidas aos não concursados da administração pública mineira, em detrimento daquelas oferecidas aos EPPGG, $46,5 \%$ dos membros e $34,2 \%$ dos exonerados afirmam haver melhores condições aos profissionais não concursados, seja atualmente ou à época na qual eram EPPGG. Nesse contexto, pode-se dizer, com base na percepção dos EPPGG, que houve uma piora no que diz respeito à desigualdade quanto ao tratamento concedido aos não concursados e aos EPPGG. 


\subsection{Gestão do desempenho}

As análises das políticas e práticas de recursos humanos do subsistema de gestão do desempenho baseiam-se nos dados constantes da Tabela 2.

Tabela 2 - Existência de políticas e práticas de gestão do desempenho para os EPPGG

\begin{tabular}{|c|c|c|c|c|c|c|c|c|c|}
\hline \multirow[t]{2}{*}{ Condição } & \multirow[t]{2}{*}{ Opção } & \multicolumn{2}{|c|}{$\begin{array}{l}\text { As avaliaçōes de } \\
\text { desempenho } \\
\text { distingue os } \\
\text { desempenhos? }\end{array}$} & \multicolumn{2}{|c|}{$\begin{array}{l}\text { As expectatıvas de } \\
\text { desempenho são } \\
\text { comunicadas pelo } \\
\text { órgão? }\end{array}$} & \multicolumn{2}{|c|}{$\begin{array}{c}\text { O desempenho demandado } \\
\text { de você enquanto EPPGG } \\
\text { está em conformidade com a } \\
\text { estratégia do órgão? }\end{array}$} & \multicolumn{2}{|c|}{$\begin{array}{c}\text { As avaliações } \\
\text { possuem regras } \\
\text { claras e confiáveis? }\end{array}$} \\
\hline & & Freq. & Perc. & Freq. & Perc. & Freq. & Perc. & Freq. & Perc. \\
\hline \multirow{5}{*}{ Membro } & Sim & 29 & $22,5 \%$ & 42 & $32,6 \%$ & 84 & $65,1 \%$ & 27 & $20,9 \%$ \\
\hline & Não & 81 & $62,8 \%$ & 75 & $58,1 \%$ & 28 & $21,7 \%$ & 81 & $62,8 \%$ \\
\hline & Não sei/não & & & & & & & & \\
\hline & se aplica & 19 & $14,7 \%$ & 12 & $9,3 \%$ & 17 & $13,2 \%$ & 21 & $16,3 \%$ \\
\hline & Total & 129 & $100 \%$ & 129 & $100 \%$ & 129 & $100 \%$ & 129 & $100 \%$ \\
\hline \multirow{5}{*}{ Exonerado } & $\mathrm{Sim}$ & 9 & $12,3 \%$ & 19 & $26,0 \%$ & 30 & $41,1 \%$ & 13 & $17,8 \%$ \\
\hline & Não & 51 & $69,9 \%$ & 46 & $63,0 \%$ & 26 & $35,6 \%$ & 45 & $61,6 \%$ \\
\hline & Não sei/não & & & & & & & & \\
\hline & se aplica & 13 & $17,8 \%$ & 8 & $11,0 \%$ & 17 & $23,3 \%$ & 15 & $20,5 \%$ \\
\hline & Total & 73 & $100 \%$ & 73 & $100 \%$ & 73 & $100 \%$ & 73 & $100 \%$ \\
\hline \multirow{5}{*}{$\begin{array}{l}\text { Membros }+ \\
\text { Exonerados }\end{array}$} & Sim & 38 & $18,8 \%$ & 61 & $30,2 \%$ & 114 & $56,4 \%$ & 40 & $19,8 \%$ \\
\hline & Não & 132 & $65,3 \%$ & 121 & $59,9 \%$ & 54 & $26,7 \%$ & 126 & $62,4 \%$ \\
\hline & Não sei/ não & & & & & & & & \\
\hline & se aplica & 32 & $15,8 \%$ & 20 & $9,9 \%$ & 34 & $16,8 \%$ & 36 & $17,8 \%$ \\
\hline & Total & 202 & $100 \%$ & 202 & $100 \%$ & 202 & $100 \%$ & 202 & $100 \%$ \\
\hline
\end{tabular}

Fonte: elaborado pelos autores

Quanto às avaliações de desempenho, 62,8\% dos membros e $69,9 \%$ dos exonerados afirmaram que as avaliações de desempenho realizadas não permitem ou não permitiam à sua época a distinção dos desempenhos dos EPPGG, demonstrando que, para grande parte dos EPPGG, as avaliações não cumprem seu papel primordial, que se refere a distinguir as contribuições de cada servidor (Tabela 2).

Acredita-se que essa condição esteja associada ao fato de que, conforme afirma Longo (2007), os dirigentes na administração pública, bem como os instrumentos de avaliação, tendem ao paternalismo, o que resultaria em avaliações pouco eficazes no sentido de reconhecer as diferentes contribuições dos profissionais.

Pode-se dizer, no entanto, que houve uma melhora nessa política, se comparadas as percepções de membros e exonerados.
Essa melhora pode estar associada à implementação da ADI, que ocorreu em 2003.

Ainda no que se refere à gestão do desempenho, $62,8 \%$ dos membros e $61,6 \%$ dos exonerados asseguram não haver critérios de avaliações de desempenho com regras claras, objetivas e confiáveis, seja atualmente ou à sua época, respectivamente. A similaridade dos percentuais nos permite concluir que houve uma persistência do problema em voga.

Essa percepção pode estar relacionada ao fato de que se aplicam os mesmos critérios para os diversos profissionaispresentesnoórgão, nãohavendo uma avaliação diferenciada para o EPPGG. $\mathrm{E}$, também, pode estar relacionada ao fato de que, de maneira geral, os desempenhos auferidos pelas avaliações não divergem 
entre os profissionais, sinalizando a falta de clareza, confiança e objetividade das regras. Acredita-se que, na percepção dos EPPGG, se as avaliações de desempenho não alcançam o principal objetivo, que é avaliar as diferentes contribuições dos profissionais, uma das razões para tal seria a ausência desses critérios nas regras das avaliações.

Além da falta de confiança do instrumento, por parte dos funcionários, 0 fato de as avaliações de desempenho não revelarem a real contribuição de cada um e não apresentarem regras claras e objetivas pode trazer prejuízo para a realização de uma gestão de pessoas integrada. Isso ocorre porque, segundo autores como Levinson (1997), Dutra (2007) e Longo
(2007), as avaliações de desempenho, se bem gerenciadas, fornecem importante subsídio para a concessão de remunerações mais justas e também para 0 desenvolvimento adequado dos profissionais. No caso em análise, de acordo com a opinião dos EPPGG, as avaliações de desempenho não possuem aplicação adequada, o que pode ocasionar, também, problemas nos subsistemas de compensação e desenvolvimento relacionados à gestão dessa carreira.

\subsection{Gestão da compensação}

As análises das políticas e práticas de recursos humanos do subsistema de gestão da compensação baseiam-se nos dados constantes da Tabela 3.

Tabela 3 - Existência de políticas e práticas de gestão da compensação para os EPPGG

\begin{tabular}{|c|c|c|c|c|c|c|c|c|c|c|c|c|c|c|c|}
\hline \multirow[b]{2}{*}{ Condição } & \multirow[b]{2}{*}{ Opção } & \multicolumn{2}{|c|}{$\begin{array}{c}\text { Existem } \\
\text { retribuições } \\
\text { variáveis } \\
\text { baseadas no } \\
\text { desempenho? }\end{array}$} & \multicolumn{2}{|c|}{$\begin{array}{c}\text { A } \\
\text { compensação } \\
\text { financeira } \\
\text { retrata a } \\
\text { contribuição } \\
\text { aos } \\
\text { resultados? }\end{array}$} & \multicolumn{2}{|c|}{$\begin{array}{c}\text { A } \\
\text { classificação } \\
\text { dos cargos } \\
\text { permite uma } \\
\text { progressão por } \\
\text { desempenho? }\end{array}$} & \multicolumn{2}{|c|}{$\begin{array}{l}\text { Há equidade } \\
\text { externa nas } \\
\text { retribuições? }\end{array}$} & \multicolumn{2}{|c|}{$\begin{array}{c}\text { Há benefícios } \\
\text { extra- } \\
\text { salariais? }\end{array}$} & \multicolumn{2}{|c|}{$\begin{array}{l}\text { Há } \\
\text { reconhecimen } \\
\text { to não } \\
\text { monetário? }\end{array}$} & \multicolumn{2}{|c|}{$\begin{array}{c}\text { Há } \\
\text { compressão } \\
\text { vertical e } \\
\text { horizontal dos } \\
\text { salários? }\end{array}$} \\
\hline & & Freq. & Perc. & Freq. & Perc. & Freq. & Perc. & Freq. & Perc. & Freq. & Perc. & Freq. & Perc. & Freq. & Perc. \\
\hline \multirow{5}{*}{ Membro } & Sim & 98 & $76,0 \%$ & 14 & $10,9 \%$ & 23 & $17,8 \%$ & - & - & 30 & $23,3 \%$ & 29 & $22,7 \%$ & 94 & $72,9 \%$ \\
\hline & Não & 21 & $16,3 \%$ & 97 & $75,2 \%$ & 93 & $72,1 \%$ & 117 & $90,7 \%$ & 95 & $73,6 \%$ & 91 & $71,1 \%$ & 22 & $17,1 \%$ \\
\hline & Não sei/ & & & & & & & & & & & & & & \\
\hline & & 10 & $7,8 \%$ & 18 & $14,0 \%$ & 13 & $10,1 \%$ & 12 & $9,3 \%$ & 4 & $3,1 \%$ & 8 & $6,3 \%$ & 13 & $10,1 \%$ \\
\hline & Total & 129 & $100 \%$ & 129 & $100 \%$ & 129 & $100 \%$ & 129 & $100 \%$ & 129 & $100 \%$ & 128 & $100 \%$ & 129 & $100 \%$ \\
\hline \multirow{5}{*}{ Exonerado } & Sim & 27 & $37,0 \%$ & 6 & $8,2 \%$ & 7 & $9,9 \%$ & - & - & 17 & $23,3 \%$ & 11 & $15,1 \%$ & 37 & $50,7 \%$ \\
\hline & Não & 40 & $54,8 \%$ & 61 & $83,6 \%$ & 51 & $71,8 \%$ & 61 & $83,6 \%$ & 52 & $71,2 \%$ & 55 & $75,3 \%$ & 20 & $27,4 \%$ \\
\hline & $\begin{array}{l}\text { Não sei/ } \\
\text { não se }\end{array}$ & & & & & & & & & & & & & & \\
\hline & aplica & 6 & $8,2 \%$ & 6 & $8,2 \%$ & 13 & $18,3 \%$ & 12 & $16,4 \%$ & 4 & $5,5 \%$ & 7 & $9,6 \%$ & 16 & $21,9 \%$ \\
\hline & Total & 73 & $100 \%$ & 73 & $100 \%$ & 71 & $100 \%$ & 73 & $100 \%$ & 73 & $100 \%$ & 73 & $100 \%$ & 73 & $100 \%$ \\
\hline \multirow{6}{*}{$\begin{array}{l}\text { Membros + } \\
\text { Exonerados }\end{array}$} & & 125 & $61,9 \%$ & 20 & $9,9 \%$ & 30 & $15,0 \%$ & - & - & 47 & $23,3 \%$ & 40 & $19,9 \%$ & 131 & $64,9 \%$ \\
\hline & Não & 61 & $30,2 \%$ & 158 & $78,2 \%$ & 144 & $72,0 \%$ & 178 & $88,1 \%$ & 147 & $72,8 \%$ & 146 & $72,6 \%$ & 42 & $20,8 \%$ \\
\hline & Não sei/ & & & & & & & & & & & & & & \\
\hline & não se & & & & & & & & & & & & & & \\
\hline & aplica & 16 & & 24 & $11,9 \%$ & 26 & $13,0 \%$ & 24 & $11,9 \%$ & 8 & & 15 & $7,5 \%$ & 29 & $14,4 \%$ \\
\hline & Total & 202 & $100 \%$ & 202 & $100 \%$ & 200 & $100 \%$ & 202 & $100 \%$ & 202 & $100 \%$ & 201 & $100 \%$ & 202 & $100 \%$ \\
\hline
\end{tabular}

Fonte: elaborado pelos autores 
Com relação à gestão da compensação, $76,0 \%$ dos membros da carreira e 37,0\% dos exonerados afirmam existir retribuição variável baseada no desempenho individual, atualmente ou à sua época.

Sabe-se, por meio de pesquisa documental, que o Estado de Minas Gerais instituiu não apenas para o EPPGG, mas para todos os servidores, a retribuição variável, denominada "prêmio por produtividade". Esse benefício está em lei desde 2003. No entanto, de acordo com as regras e critérios vigentes até 2006, poucos órgãos e servidores gozavam de tal benefício. Com as mudanças na legislação, a partir de 2007, o recurso financeiro e orçamentário destinado para o prêmio passou a ser garantido na Lei Orçamentária Anual, ampliando o número de beneficiários, representado, hoje, pela totalidade dos servidores do estado.

A existência do prêmio por produtividade pode, então, justificar o percentual daqueles que afirmaram haver retribuição variável. A pior percepção dos exonerados pode estar relacionada ao fato de que, no momento em que eles atuavam como EPPGG, o prêmio de fato não existia, ou existia, mas com limitações que restringiam o número de beneficiários. Acredita-se, também, que uma parcela dos que responderam não existir retribuição variável pode se justificar pelo fato de que, conforme destacado anteriormente, para grande parte dos EPPGG, a avaliação de desempenho não é eficiente para distinguir os desempenhos, consequentemente, a remuneração variável também não se basearia no desempenho de cada profissional.

A existência de remuneração variável, na percepção da maioria dos EPPGG, vai ao encontro da tendência das organizações, sejam públicas ou privadas, de implementarem essas formas de remuneração, em complementação à remuneração funcional. De acordo com
Rabelo-Santos (2010), as organizações que vêm adotando uma filosofia com base no trabalho em equipe, no desenvolvimento contínuo do profissional e na busca de resultados estão dando preferência à remuneração composta, que, além da remuneração funcional tradicional, utiliza-se da remuneração variável.

Já sobre a equidade externa, 90,7\% dos membros e $83,6 \%$ dos exonerados afirmaram não existir, demonstrando que os salários pagos no mercado de referência são maiores do que os pagos aos EPPGG. É importante destacar que nenhum EPPGG, seja membro ou exonerado, respondeu haver equidade externa, de maneira que, desconsiderando os $11,9 \%$ que não souberam responder, os EPPGG foram unânimes em negar a existência de tal equidade (Tabela 3). Outra consideração a ser feita refere-se ao fato de que, diante dos diferentes percentuais entre membros e exonerados, pode-se inferir que, na percepção dos EPPGG, a desigualdade quanto aos salários de referência do mercado aumentou ao longo dos anos, não obstante a reestruturação da carreira ocorrida em 2003.

De acordo com Longo (2007), a ausência de equilíbrio externo nas compensações provoca, muitas vezes, a perda do profissional para outras organizações. Por essa razão, pode-se dizer que o desequilíbrio externo percebido pelos EPPGG pode ocasionar dificuldade de retenção desses profissionais pelo governo mineiro.

Outra variável considerada na gestão da compensação refere-se à existência de benefícios extrassalariais, tais como vale-refeição, vale-transporte e assistência médica. Vinte e três vírgula três por cento dos EPPGG, membros e exonerados, 
responderam haver esse benefício. Sabese, por meio de pesquisa documental, que a concessão desses benefícios é uma prática adotada por alguns órgãos do Estado de Minas Gerais, não se conformando, então, como uma política generalizada para todos os membros da carreira, o que pode justificar as diferentes afirmações. A similaridade entre os percentuais de membros e exonerados permite concluir que não houve avanço ou retrocesso ao longo dos anos na concessão desse benefício.

\subsection{Gestão do desenvolvimento}

As análises das políticas e práticas de recursos humanos do subsistema de gestão do desenvolvimento baseiam-se nos dados constantes da Tabela 4.

Tabela 4 - Existência de políticas e práticas de gestão do desenvolvimento para os EPPGG

\begin{tabular}{|c|c|c|c|c|c|c|c|c|c|c|c|}
\hline \multirow[b]{2}{*}{ Condição } & \multirow[b]{2}{*}{ Opção } & \multicolumn{2}{|c|}{$\begin{array}{c}\text { Existem planos } \\
\text { de carreira que } \\
\text { adequem as } \\
\text { expectativas dos } \\
\text { EPPGG com as } \\
\text { necessidades do } \\
\text { órgão? }\end{array}$} & \multicolumn{2}{|c|}{$\begin{array}{c}\text { Existem barreiras } \\
\text { ou limitações } \\
\text { formais para a } \\
\text { progressão e } \\
\text { promoção? }\end{array}$} & \multicolumn{2}{|c|}{$\begin{array}{c}\text { Há capacitação } \\
\text { para } \\
\text { complementar a } \\
\text { formação incial } \\
\text { do EPPGG? }\end{array}$} & \multicolumn{2}{|c|}{$\begin{array}{c}\text { O } \\
\text { desenvolvimento } \\
\text { profíssional é } \\
\text { baseado nas } \\
\text { avaliações de } \\
\text { desempenho? } \\
\end{array}$} & \multicolumn{2}{|c|}{$\begin{array}{c}\text { As promoções e } \\
\text { progressões } \\
\text { baseiam-se nas } \\
\text { avaliações de } \\
\text { desempenho? }\end{array}$} \\
\hline & & Freq. & Perc. & Freq. & Perc. & Freq. & Perc. & Freq. & Perc. & Freq. & Perc. \\
\hline \multirow{5}{*}{ Membro } & Sim & 13 & $10,1 \%$ & 97 & $77,0 \%$ & 57 & $44,5 \%$ & 13 & $10,1 \%$ & 33 & $25,6 \%$ \\
\hline & Não & 106 & $82,2 \%$ & 18 & $14,3 \%$ & 62 & $48,4 \%$ & 92 & $71,3 \%$ & 68 & $52,7 \%$ \\
\hline & Não sei/ não & & & & & & & & & & \\
\hline & se aplica & 10 & $7,8 \%$ & 11 & $8,7 \%$ & 9 & $7,0 \%$ & 24 & $18,6 \%$ & 28 & $21,7 \%$ \\
\hline & Total & 129 & $100 \%$ & 126 & $100 \%$ & 128 & $100 \%$ & 129 & $100 \%$ & 129 & $100 \%$ \\
\hline \multirow{5}{*}{ Exonerado } & Sim & 4 & $5,5 \%$ & 43 & $59,7 \%$ & 21 & $29,2 \%$ & 2 & $2,7 \%$ & 15 & $20,5 \%$ \\
\hline & Não & 56 & $76,7 \%$ & 10 & $13,9 \%$ & 46 & $63,9 \%$ & 56 & $76,7 \%$ & 36 & $49,3 \%$ \\
\hline & Não sei/ não & & & & & & & & & & \\
\hline & se aplica & 13 & $17,8 \%$ & 19 & $26,4 \%$ & 5 & $6,9 \%$ & 15 & $20,5 \%$ & 22 & $30,1 \%$ \\
\hline & Total & 73 & $100 \%$ & 72 & $100 \%$ & 72 & $100 \%$ & 73 & $100 \%$ & 73 & $100 \%$ \\
\hline \multirow{5}{*}{$\begin{array}{l}\text { Membros + } \\
\text { Exonerados }\end{array}$} & Sim & 17 & $8,4 \%$ & 140 & $70,7 \%$ & 78 & $39,0 \%$ & 15 & $7,4 \%$ & 48 & $23,8 \%$ \\
\hline & Não & 162 & $80,2 \%$ & 28 & $14,1 \%$ & 108 & $54,0 \%$ & 148 & $73,3 \%$ & 104 & $51,5 \%$ \\
\hline & Não sei/ não & & & & & & & & & & \\
\hline & se aplica & 23 & $11,4 \%$ & 30 & $15,2 \%$ & 14 & $7,0 \%$ & 39 & $19,3 \%$ & 50 & $24,8 \%$ \\
\hline & Total & 202 & $100 \%$ & 198 & $100 \%$ & 200 & $100 \%$ & 202 & $100 \%$ & 202 & $100 \%$ \\
\hline
\end{tabular}

Fonte: elaborado pelos autores

A primeira questão feita aos EPPGG refere-se à existência de planos de carreira que adéquem as expectativas desses profissionais às necessidades organizacionais. Quanto à percepção dos EPPGG, tem-se que $82,2 \%$ dos membros e $76,7 \%$ dos exonerados afirmaram não existir essa adequação. Embora grande parte dos membros e exonerados não reconheça a aplicação dessa política, percebe-se uma relativa melhora ao longo dos anos.
De acordo com Dutra (2007), essa adequação configura-se como um dos grandes desafios da gestão do desenvolvimento, levando, muitas vezes, a uma atuação despreparada das organizações, tratando a questão das carreiras de maneira autoritária e disfuncional.

Assim, nota-se que, na percepção dos EPPGG, o plano de carreiras existente, atualmente, para os membros, ou à época, para os exonerados, não atende as expectativas, 
ainda que tenha havido uma reestruturação da carreira em 2003. Acredita-se que, na prática, a progressão do EPPGG é dificultada pela existência de diversas exigências, principalmente quanto ao longo período necessário para a progressão.

Setenta e um vírgula três por cento dos membros e $76,7 \%$ dos exonerados afirmaram que não há ou havia articulação entre desenvolvimento profissional e avaliações de desempenho. Dessa forma, pode-se concluir que os cursos de capacitação e desenvolvimento dos EPPGG não são ofertados conforme as necessidades de capacitação e aperfeiçoamento sinalizados nas avaliações de desempenho, tornando essas capacitações menos eficientes do que poderiam ser e, ainda, comprometendo a existência de uma gestão de pessoas integrada, conforme salientado anteriormente. No entanto, podese concluir, também, pelas diferenças entre os percentuais de membros e exonerados, que a articulação entre as avaliações de desempenho e o desenvolvimento profissional obteve relativa melhora, se comparada aos períodos anteriores.

Foi perguntado aos EPPGG se as promoções e progressões concedidas a esses profissionais são baseadas nos resultados das avaliações de desempenho. Assim, $52,7 \%$ dos membros e $49,3 \%$ dos exonerados afirmaram que não. Percebe-se que a maioria dos EPPGG, embora não seja um percentual predominante, afirmou não haver relação entre as promoções e progressões concedidas e as contribuições sinalizadas nas avaliações de desempenho. Ainda, pode-se perceber uma relativa melhora na política em questão.

$O$ fato de os EPPGG considerarem que o desenvolvimento profissional e as promoções e progressões não se baseiam nas avaliações de desempenho pode estar relacionado ao fato de que grande parte destes $(65,3 \%)$ acredita que as avaliações de desempenho não são eficazes, não identificando, portanto, as necessidades e capacidades de cada um, conforme anteriormente discutido.

De acordo com Oliveira et al. (2009), os sistema de progressão e promoção devem compor-se não apenas de regras de tempo de serviço mas também de indicadores de gestão do desempenho e de desenvolvimento, como a participação em cursos de aperfeiçoamento, o que reforçaria, ainda, uma gestão integrada de pessoas.

\subsection{Gestão das relações humanas e sociais}

As análises das políticas e práticas de recursos humanos do subsistema de gestão das relações humanas e sociais baseiam-se nos dados constantes da Tabela 5. 
Tabela 5 - Existência de políticas e práticas de gestão das relações humanas e sociais para os EPPGG

\begin{tabular}{|c|c|c|c|c|c|c|c|c|c|c|c|c|c|}
\hline \multirow[b]{2}{*}{ Condição } & \multirow[b]{2}{*}{ Opção } & \multicolumn{2}{|c|}{$\begin{array}{c}\text { Há } \\
\text { autonomia } \\
\text { individual } \\
\text { para decidir } \\
\text { sobre o } \\
\text { trabalho? }\end{array}$} & \multicolumn{2}{|c|}{$\begin{array}{c}\text { Há } \\
\text { cooperação } \\
\text { entre os } \\
\text { servidores? }\end{array}$} & \multicolumn{2}{|c|}{\begin{tabular}{|} 
No órgão em \\
que você \\
trabalha, há um \\
clima \\
organizacional \\
agradável?
\end{tabular}} & \multicolumn{2}{|c|}{$\begin{array}{c}\text { Há } \\
\text { comunicação } \\
\text { do órgão para } \\
\text { fortalecer o } \\
\text { comprometime } \\
\text { nto e difundir } \\
\text { as decisões? }\end{array}$} & \multicolumn{2}{|c|}{$\begin{array}{c}\text { Há práticas de } \\
\text { saúde laboral } \\
\text { para os } \\
\text { EPPGG? }\end{array}$} & \multicolumn{2}{|c|}{$\begin{array}{c}\text { Há benefícios } \\
\text { de assistência } \\
\text { social para os } \\
\text { EPPGG? }\end{array}$} \\
\hline & & Freq. & Perc. & Freq. & Perc. & Freq. & Perc. & Freq. & Perc. & Freq. & Perc. & Freq. & Perc. \\
\hline \multirow{4}{*}{ Membro } & Sim & 64 & $50,0 \%$ & 67 & $52,3 \%$ & 77 & $60,2 \%$ & 33 & $25,8 \%$ & 43 & $33,6 \%$ & 6 & $4,7 \%$ \\
\hline & Não & 59 & $46,1 \%$ & 48 & $37,5 \%$ & 47 & $36,7 \%$ & 86 & $67,2 \%$ & 74 & $57,8 \%$ & 94 & $73,4 \%$ \\
\hline & $\begin{array}{l}\text { Não sei/ } \\
\text { não se } \\
\text { aplica }\end{array}$ & 5 & $3,9 \%$ & 13 & $10,2 \%$ & 4 & $3,1 \%$ & 9 & $7,0 \%$ & 11 & $8,6 \%$ & 28 & $21,9 \%$ \\
\hline & Total & 128 & $100 \%$ & 128 & $100 \%$ & 128 & $100 \%$ & 128 & $100 \%$ & 128 & $100 \%$ & 128 & $100 \%$ \\
\hline \multirow{4}{*}{ Exonerado } & $\operatorname{Sim}$ & 32 & $43,8 \%$ & 31 & $42,5 \%$ & 47 & $65,3 \%$ & 11 & $15,1 \%$ & 8 & $11,1 \%$ & 3 & $4,1 \%$ \\
\hline & Não & 35 & $47,9 \%$ & 29 & $39,7 \%$ & 22 & $30,6 \%$ & 53 & $72,6 \%$ & 56 & $77,8 \%$ & 48 & $65,8 \%$ \\
\hline & $\begin{array}{l}\text { Não sei/ } \\
\text { não se } \\
\text { aplica }\end{array}$ & 6 & $8,2 \%$ & 13 & $17,8 \%$ & 3 & $4,2 \%$ & 9 & $12,3 \%$ & 8 & $11,1 \%$ & 22 & $30,1 \%$ \\
\hline & Total & 73 & $100 \%$ & 73 & $100 \%$ & 72 & $100 \%$ & 73 & $100 \%$ & 72 & $100 \%$ & 73 & $100 \%$ \\
\hline \multirow{5}{*}{$\begin{array}{l}\text { Membros + } \\
\text { Exonerados }\end{array}$} & $\operatorname{Sim}$ & 96 & $47,8 \%$ & 98 & $48,8 \%$ & 124 & $62,0 \%$ & 44 & $21,9 \%$ & 51 & $25,5 \%$ & 9 & $4,5 \%$ \\
\hline & Não & 94 & $46,8 \%$ & 77 & $38,3 \%$ & 69 & $34,5 \%$ & 139 & $69,2 \%$ & 130 & $65,0 \%$ & 142 & $70,6 \%$ \\
\hline & $\begin{array}{l}\text { Não sei/ } \\
\text { não se }\end{array}$ & & & & & & & & & & & & \\
\hline & aplica & 11 & $5,5 \%$ & 26 & $12,9 \%$ & 7 & $3,5 \%$ & 18 & $9,0 \%$ & 19 & $9,5 \%$ & 50 & $24,9 \%$ \\
\hline & Total & 201 & $100 \%$ & 201 & $100 \%$ & 200 & $100 \%$ & 201 & $100 \%$ & 200 & $100 \%$ & 201 & $100 \%$ \\
\hline
\end{tabular}

Fonte: elaborado pelos autores

Com relação ao clima organizacional, $60,2 \%$ dos membros e $65,3 \%$ dos exonerados responderam ser agradável.

No que tange às relações interpessoais e ao clima organizacional que permeia o EPPGG, acredita-se que, como muitos EPPGG trabalham com outros EPPGG, cria-se um espírito de grupo e um trabalho em equipe maior, promovendo a sensação de que todos estão "no mesmo barco"; ou seja, gozam de todos os prazeres e desprazeres da carreira de maneira conjunta. No entanto, observa-se relativa piora na análise do clima organizacional se comparado às percepções dos membros e exonerados.

As práticas de saúde laboral também se conformam como componente da gestão das relações humanas e sociais. Assim, para $33,6 \%$ dos membros e $11,1 \%$ dos exonerados, existem ou existiam essas práticas. Embora a percepção da maioria dos membros da carreira seja de que não há práticas de saúde laboral 
no órgão no qual estão inseridos, a significativa diferença entre os percentuais dos membros e dos exonerados permite inferir que houve uma expansão na utilização de práticas de saúde laboral, se comparada a períodos anteriores.

Sabe-se, por meio de pesquisa documental, que foi iniciado, em julho de 2009, o programa motivacional denominado "BemEstarMinas", que tem como objetivo implementar ações de comunicação interna, comemoração de datas especiais, entretenimento e qualidade de vida, entre outras, buscando a motivação e a melhoria contínua do ambiente de trabalho. No entanto, o programa foi implementado apenas em seis órgãos da administração pública mineira, o que pode justificar as diferentes percepções quanto à existência de políticas relacionadas à saúde laboral.

De acordo com Longo (2007), as políticas e práticas do subsistema de relações humanas e sociais precisam ser mais bem consideradas pelos gestores, tendo em vista que são percebidas pelos funcionários como uma forma alternativa de reconhecimento do trabalho, de remuneração complementar e, ainda, fonte de motivação.

\section{Considerações Finais}

O objetivo deste trabalho consistiu em enumerar e analisar políticas e práticas de recursos humanos existentes no Estado de Minas Gerais para os EPPGG, além de verificar em que medida a implementação dessas políticas sofreu mudanças ao longo do tempo, indicando possível melhoria ou retrocesso, sob a ótica desses profissionais.

A pesquisa realizada permitiu concluir que, da totalidade de políticas e práticas de recursos humanos listadas no questionário, apenas $28,6 \%$ são visualizadas como políticas e práticas existentes no Governo de Minas Gerais, na percepção dos EPPGG membros da carreira.
Quanto às avaliações dos subsistemas, considerando o percentual de políticas e práticas bem-avaliadas pelos EPPGG membros da carreira - ou seja, aquelas consideradas existentes no Governo de Minas Gerais para a carreira de EPPGG, sobre o total de políticas e práticas listadas no questionário para cada subsistema - podese afirmar que o subsistema de recursos humanos que possui a pior avaliação referese à gestão do desenvolvimento, de maneira que nenhuma política ou prática listada foi considerada existente pela maioria dos EPPGG.

O segundo subsistema mais mal avaliado foi o da gestão da compensação, visto que apenas uma de sete políticas avaliadas $(14,3 \%)$ foi considerada existente pelos EPPGG. O subsistema de gestão da compensação ainda se destaca pelos elevados percentuais de negação, constante em todas as políticas e práticas listadas.

Visto que o subsistema do desenvolvimento preocupa-se com a progressão na carreira, bem como com o crescimento profissional e o subsistema da compensação com a oferta de uma remuneração equitativa, e condizente com o desempenho de cada profissional, podese dizer que a questão salarial e a falta de perspectiva de carreira se conformam como questões cruciais para a melhoria da gestão dos EPPGG, como ativos estratégicos para o setor público mineiro, considerando a percepção desses profissionais.

O subsistema de gestão das relações humanas e sociais foi o mais bem avaliado, sendo que quatro das sete políticas listadas $(57,1 \%)$ foram bem avaliadas pelos EPPGG membros da carreira. Isso demonstra que o clima organizacional e as relações coletivas de trabalho não são considerados problemáticos para a maioria dos EPPGG, 
confirmando, também, o fato de que, como muitos EPPGG trabalham com profissionais da mesma carreira, as relações de trabalho podem ser mais agradáveis e cooperativas.

Por meio desta pesquisa, concluiuse, também, que $71,4 \%$ das políticas de recursos humanos analisadas sofreram melhora ao longo dos anos e 21,4\% sofreram retrocesso, sob a ótica dos EPPGG. Esta evolução é percebida quando se comparam as diferentes percepções dos membros e exonerados. Assim, embora muitas das políticas e práticas de recursos humanos listadas não sejam percebidas como implementadas, por grande parte dos EPPGG, muitas delas foram mais bem avaliadas pelos membros do que pelos exonerados. Pode-se dizer, então, que o Governo de Minas Gerais tem avançado no que tange à gestão de pessoas relacionada aos EPPGG, considerando o entendimento desses profissionais.

Ainda sobre a evolução das políticas e práticas, o subsistema que apresentou melhor evolução quanto à implementação de políticas e práticas foi o de gestão do desempenho, sendo que todas as políticas e práticas listadas apresentaram melhoria ao longo dos anos, de acordo com a opinião dos EPPGG. Acredita-se que esse fato esteja associado à implementação da ADI, a partir de 2003, que, embora apresente disfunções e lacunas, representa o início da avaliação das diferentes contribuições dos servidores na administração pública mineira.

O segundo subsistema que apresentou melhor evolução foi 0 de desenvolvimento, sendo que $80,0 \%$ das políticas e práticas listadas sofreram melhora, na percepção dos EPPGG. É importante destacar que, não obstante essa melhoria, esse subsistema possui a pior avaliação quanto à implementação de suas políticas e práticas, na percepção dos EPPGG. Essa situação indica que as defasagens desse subsistema eram ainda maiores anteriormente.

Por sua vez, o subsistema que apresentou pior evolução refere-se ao subsistema de gestão da compensação, sendo que apenas quatro das sete políticas listadas $(57,1 \%)$ sofreram melhoras ao longo dos anos, sob a ótica dos respondentes. Assim, tem-se que a busca por uma compensação conforme desempenho, por equidade interna e externa, bem como por salários mais justos e atrativos, deve ser imperativa para o governo mineiro, com relação à gestão dos EPPGG.

Diante das avaliações dos subsistemas, pode-se dizer que, considerando a opinião dos EPPGG, o Governo de Minas Gerais ainda não conseguiu implementar um modelo de gestão de pessoas integrado, ao menos no que se refere à gestão desses profissionais. Percebe-se uma desconexão entre os diferentes subsistemas, principalmente os de gestão de desempenho, desenvolvimento e compensação, de maneira que um não fornece subsídios adequados ao outro. Tem-se, no caso estudo, que as avaliações de desempenho não diferenciam adequadamente as contribuições de cada profissional, de acordo com a opinião dos EPPGG, criando, portanto, prejuízos na concessão de remuneração variável e na oferta de políticas de desenvolvimento que sejam condizentes com as necessidades de formação e capacitação de cada EPPGG.

Outra conclusão importante refere-se ao fato de que grande parte das políticas e práticas de recursos humanos foi implementada pelo Estado de Minas Gerais de maneira uniforme a todos os servidores do estado, tais como a $A D I$, a reestruturação de carreiras e o prêmio por produtividade. Ainda, outras políticas foram aplicadas apenas em alguns órgãos, tais como benefícios extrassalariais (vale-transporte e vale-refeição) e o programa Bem-Estar Minas. 
Acredita-se que essas condições influenciam de maneira negativa a percepção dos EPPGG quanto à existência de políticas e práticas de recursos humanos.

Cabe destacar que a análise baseouse, primordialmente, na opinião dos EPPGG acerca das políticas e práticas implementadas pelo governo mineiro e, por esse motivo, não pode ser entendida como a avaliação da carreira propriamente dita. No entanto, acredita-se que essas opiniões são importantes, pois, se as recentes transformações pelas quais vem passando a área de gestão de pessoas estão associadas à valorização dos indivíduos e ao entendimento de que estes são fundamentais para o alcance dos resultados organizacionais, suas opiniões precisam ser consideradas, para que as organizações possam melhor gerenciá-los e conduzi-los à realização de seus objetivos. Além disso, conforme afirmam Oliveira e outros (2009), trata-se de realidade vivenciada que deve ser considerada como válida para a melhoria da gestão de pessoas no setor público.

Por fim, sugere-se que pesquisas futuras sejam realizadas no sentido de verificar a existência de políticas e práticas de recursos humanos em outras carreiras, no intuito de expandir o diagnóstico acerca da gestão de pessoas no Estado de Minas Gerais, de modo a propor melhorias não apenas para uma carreira específica, mas para a gestão de recursos humanos no âmbito do estado.

\section{REFERÊNCIAS BIBLIOGRÁFICAS}

ALBUQUERQUE, L. O papel estratégico de recursos humanos. São Paulo: FEA/USP, 1987.

AMBLARD, H. Gestão de recursos humanos. Lisboa: Presença, 1989.
BARBOSA, A. C. Q. et al. Competências no Brasil: um olhar sobre os modelos de grandes organizações de Minas Gerais, Rio de Janeiro, Rio Grande do Sul e São Paulo. Belo Horizonte: UFMG/CNPQ, 2005. Relatório de pesquisa.

BERNARDO, R. A. A carreira de especialista em políticas públicas e gestão governamental (EPPGG) como instrumento transformador da realidade estatal: a experiência de Minas Gerais. In: Congresso Consad de Gestão Pública, 3. 2010, Brasília. Anais do III CONSAD, Brasília, DF, 2010.

CAMPOS, E. S. A.; Bernardi, M. M. E. Comparação de rendimentos públicoprivados e a carreira de EPPGG em Minas Gerais: uma defesa da diferenciação na gestão de pessoas do Setor Público. In: ENCONTRO NACIONAL DA ANPAD, 32, 2008, Rio de Janeiro. Anais do XXXII ENANPAD, Rio de Janeiro, RJ, 2008.

COSTA, F. L. Condicionantes da reforma do Estado no Brasil. In: MARTINS, P. E. M.; PIERANTI, O. P. Estado e gestão pública: visões do Brasil contemporâneo. 2. ed. Rio de Janeiro: Fundação Getulio Vargas, 2006. p. 133-158.

DUTRA, J. S. Administração de carreiras: uma proposta para repensar a gestão de pessoas. São Paulo: Atlas, 2007.

DUTRA, J. S. Competências. São Paulo: Atlas, 2004.

GAETANI, F. Capacitação de recursos humanos no serviço público: problemas e impasses. Revista do Serviço Público, Brasília: ENAP, ano 45, v. 118, 1998. 
LACOMBE, B. M. B.; TONELLI, M. J. O discurso e a prática: o que nos dizem os especialistas e o que nos mostram as práticas das empresas sobre os modelos de gestão de recursos humanos. Revista de Administração Contemporânea, v. 5, n. 2, p. 157-174, 2005.

LEVINSON, H. Avaliação de que desempenho? In: Vroom, V. H. Gestão de pessoas, não de pessoal. Rio de Janeiro: Campus, 1997. parte II, cap. 3, p. 189-203.

LONGO, F. Mérito e flexibilidade: a gestão das pessoas no setor público. São Paulo: Fundap, 2007.

MARCONI, N. Políticas integradas de recursos humanos para o setor público. In: LEVY, E.; DRAGO, P. A. (Orgs.). Gestão pública no Brasil contemporâneo. São Paulo: Fundep, 2005.

MARCONI, N. Uma radiografia do emprego público no Brasil: análise e sugestões de políticas. In: LOUREIRO, M. R.; ABRUCIO, F. L.; PACHECO, R. S. (Orgs.). Burocracia e política no Brasil. Rio de Janeiro: FGV, 2010.

MASLOW, A. H. Motivation and personality. New York: Harper, 1954.

MINAS GERAIS, Decreto 43.576, de 9.9.2003a. Estabelece o plano de carreira para os servidores do Estado de Minas Gerais. Assembleia Legislativa. Disponível em: http:// www.almg.gov.br. Acesso em: 15 jul. 2009.

MINAS GERAIS, Decreto 43.672, de 4.12.2003b. Estabelece as diretrizes e define os critérios e os sistemas de avaliação de desempenho individual do Poder Executivo Estadual. Assembleia Legislativa. Disponível em: http://www.almg.gov.br. Acesso em: 15 jul.
2009.

MINAS GERAIS, Lei 13.085, de 31.12.1998. Cria as carreiras que menciona, institui a gratificação de desempenho e produtividade individual e institucional e dá outras providências. Assembleia Legislativa. Disponível em: http://www.almg.gov. br. Acesso em: 15 jul. 2009.

MINAS GERAIS, Lei 18.794, de 29.6. 2010. Estabelece a estrutura da carreira estratégica de especialista em políticas públicas e gestão governamental, altera as tabelas de vencimento das carreiras policiais civis e dá outras providências. Assembleia Legislativa. Disponível em: http://www.almg.gov.br. Acesso em: 15 jul. 2009.

NOGUEIRA, R. P.; Santana, J. P. Human resource management and public sector reforms: trends and origins of a new approach. IPEA, texto para discussão n. 888. Brasília, 06/2002.

OLIVEIRA, M. P. et al. Aprimoramento da gestão da carreira do especialista em políticas públicas e gestão governamental. Ministério do Planejamento. 2009. Disponível em: http://www. planejamento.gov.br/secretarias/upload/Arquivos/ seges/EPPGG/outros/produto_II_consolidacao_ documentos.pdf. Acesso em: 05 abr. 2013.

PAULA, A. P. P. Por uma nova gestão pública: limites e potencialidades da experiência contemporânea. Rio de Janeiro: FGV, 2005.

PEREIRA, L. C. B. Reforma do estado para a cidadania: a reforma gerencial brasileira na perspectiva internacional. São Paulo: 34; Brasília: ENAP, 1998.

RABELO-SANTOS, A. Sistemas de remuneração, justiça e suporte organizacional, In: PANTOJA, M. J. e outros. Gestão de pessoas: bases teóricas 
e experiências no setor público. Brasília: Enap, Harvard Business School, 2001. 2010.

RAMIÓ, C; Salvador, M. Intituciones y reforma VASCONCELOS, I. F. G. O modelo político e o del sector público: el impacto de los referentes institucionales en la gestión de recursos humanos de las administraciones públicas latinoamericanas. In: Longo, F.; Ramió, C. (Eds.). La profissionalización del empleo público en América Latina. Barcelona: Fundación Cidob, 2008. modelo instrumental de gestão de pessoas: uma análise crítica das contradições discursoprática na implementação de $\mathrm{TI}$ em duas organizações nacionais. Relatório de pesquisa n. 11/2004. FGV-EASP/GVPESQUISA, 2004.

VILHENA, R. et al. O choque de gestão em Minas Gerais: políticas de gestão pública para o desenvolvimento. Belo Horizonte: UFMG,

ULRICH, D. et al. The HR scorecard. Boston: 2006. 